\title{
Toxicities of anticancer drugs and its management
}

\author{
Ambili Remesh ${ }^{\mathrm{a}, *}$
}

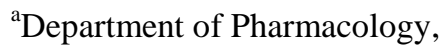

Dr. Somervell Memorial CSI

Medical College, Karakonam,

Trivandrum, Kerala, India

Received: 2 August 2012

Accepted: 7 August 2012

\section{*Correspondence to:}

Dr. Ambili Remesh,

Email:

ambiliremesh@yahoo.com

\begin{abstract}
One of the characteristics that distinguish anticancer agents from other drugs is the frequency and severity of side effects at therapeutic doses. Most cytotoxic drugs target rapidly multiplying cells and the putative targets are the nucleic acids and their precursors, which are rapidly synthesised during cell division. Many solid tumours have a lower growth fraction than the normal bone marrow, gastro intestinal lining, reticuloendothelial system and gonads. Drugs affect these tissues in a dose dependant manner and there is individual susceptibility also. So toxicities are more frequently associated with these tissues. The side effects may be acute or chronic, self-limited, permanent, mild or potentially life threatening. Management of these side effects is of utmost importance because they affect the treatment, tolerability and overall quality of life. This paper gives an overview of different toxicities of anticancer drugs and its management.
\end{abstract}

Keywords: Cytotoxicity, Anticancer drugs, Toxicity, Management of side effects, Antineoplastic agents

\section{INTRODUCTION}

Various chemotherapeutic agents in single, in combination and in conjunction with surgery, radiotherapy and immunotherapy are used widely for the treatment of variety of neoplastic diseases. Currently chemotherapy has a role in different clinical settings like induction treatment for advance diseases, as an adjunct to local methods of treatment, and as primary treatment for localised disease. ${ }^{1}$

Clinically useful antineoplastic agents exhibit selective toxicity to malignant cells. Many regenerating tissues possess high proliferative capacity rivalling malignant tissues and on exposure to chemotherapy, such tissues (bone marrow elements, gastrointestinal tract mucosa, hair follicles) endure the most of toxic effects The antineoplastic agents have the lowest therapeutic indices of any drug and as such they cause frequent and predictable multi system toxicity. ${ }^{2}$ They are mainly acute toxicity in immediate post therapy periods which are usually reversible and long-term toxicity, which are delayed and irreversible. These increase the morbidity and mortality of treatment.

Chemotherapy drugs are combined with a view of inducing rapid cytoreduction and the overlapping of toxicities is considered when drugs are used in optimal dose and schedules. Approaches to the reduction of chemotherapy-induced toxicity include dose reduction, use of alternate drugs or their analogues, growth factors, and cytoprotective agents. ${ }^{2}$

Common toxicities encountered are haematological, gastrointestinal, skin and hair follicle toxicity, nervous system toxicity, local toxicity, metabolic abnormalities, hepatic toxicity, urinary tract toxicity, cardiac toxicity, pulmonary toxicity, gonadal toxicity etc. ${ }^{3}$ These toxicities, drugs causing this and management of these toxicities are discussed in subsequent sections of this paper.

\section{HAEMATOLOGICAL TOXICITY}

Peripheral cytopenia from bone marrow suppression is a frequent dose limiting side effect of chemotherapy and can manifest as acute and chronic marrow damage. ${ }^{4}$ Chemotherapy may result in the destruction of activity of proliferating haematopoietic precursor cells, leading to deprivation of formed elements, and incidence of life threatening haemorrhage and infection. ${ }^{5}$ The drugs causing haematological toxicity are mentioned in Table 1.

\section{Management}

Management varies from dose reduction to treatment for neutropenic sepsis. Patient who develop grade 4 toxicity 
require hospitalisation, treatment of infection or bleeding. Courses of chemotherapy are postponed until myelosuppression abates. Colony stimulating factors like erythropoietin, Darbopoietin alpha, G-CSF, GM-CSF, various cytokines, platelet transfusions etc are used in the management. ${ }^{6}$

Table 1: Drugs causing bone marrow depression.

\begin{tabular}{|llll|}
\hline Carboplatin & Dactinomycin & Vinblastine & Doxorubicin \\
Chlorambucil & Mitomycin & Melphelan & Gemcitabine \\
Oxaliplatin & Fludarabine & Oxaliplatin & Methotrexate \\
Cyclophosphamide & Mustine & Idarubicin & Daunorubicin \\
Cytarabine & Topotecan & Irinotecan & Paclitaxel \\
Vinorelbine & FU & Rituximab & Hydroxyurea \\
Ifosamide & Mitoxantrone & Transtuzumab & \\
& & & \\
\hline
\end{tabular}

\begin{abstract}
Anaemia
The aetiology of anaemia in the patient with cancer is multifactorial and includes blood loss, absent nutritional stores, marrow infiltration and direct effect of cytotoxic drugs. ${ }^{7}$ The symptoms associated with mild to moderate anaemia can negatively affect the person's normal functional ability and quality of life. A thorough laboratory investigation is necessary to assess the cause of anaemia. The decision for transfusion should be based on the patient's symptom in concert with laboratory data. Anticancer drugs implicated in the development of anaemia are in the Table $2 .^{5}$
\end{abstract}

Table 2: Anticancer drugs causing anaemia.

\begin{tabular}{|lll|}
\hline $\begin{array}{l}\text { Cisplatine } \\
\text { Docetaxel }\end{array}$ & $\begin{array}{l}\text { Altretamine } \\
\text { Cytarabine }\end{array}$ & $\begin{array}{l}\text { Topotecan } \\
\text { Paclitaxel }\end{array}$ \\
\hline
\end{tabular}

Table 3: Drugs causing thrombocytopenia.

\begin{tabular}{|ll|}
\hline Dacarbazine & Lomustine \\
Carboplatine & Mitomycin \\
5-flurouracil & Thiotepa \\
\hline
\end{tabular}

\section{Management}

1. Packed red cell transfusion

2. Erythropoietin, Epoetin alpha

3. Darbopoietin.

\section{Neutropenia}

Definition: Absolute neutrophil count $<500$ cell $/ \mathrm{mm}^{3}$ and count $<1000$ cell $/ \mathrm{mm}^{3}$ with a predicted decrease to $500 \mathrm{cell} / \mathrm{mm}^{3}{ }^{8}$. There is inverse relationship between the degree and duration of neutropenia and risk of infection. For afebrile neutropenic patients the goal is to prevent infectious complication and detect infection at the earliest stage. The development of fever in neutropenics represents an urgent problem requiring prompt assessment. This is because neutropenics have lack of signs and symptoms, rapid progression of infection, unusual site of involvement, unusual infectious organisms. $^{8}$

\section{Management}

Apart from general management, Bone Marrow Growth Factors reduces the frequency and severity of neutropenia and infection, sepsis and other complications due to neutropenia. The recombinant growth factors used to stimulate growth of neutrophils are GCSF (Filgrastim, Lenograstim and Pegfilgrastim) and GMCSF (Sargramostim, Molgramostim, Regramostim). ${ }^{9}$

Pizzo and Schimpff identified four general principles to minimise the risk of infection in patients with cancer. ${ }^{10}$
a) Augment the host defence mechanism
b) Preserving the natural barrier of defence
c) Reducing the environmental organisms
d) Minimising endogenous micro flora.

These general principles remain relevant even today and provide the foundation for essential care practices that are adjunct to antimicrobial therapy. Prompt intervention of empirical chemotherapy is essential in the management of neutropenia. ${ }^{11}$ The choice of antibiotics is influenced by the ever-changing environment, individual susceptibility, pattern and emergence of resistant strains. ${ }^{8}$

Interventions to promote mechanical barrier integrity include

1. Avoidance of injections whenever possible

2. Strategies to prevent skin breakdown

3. Avoidance of bladder catheterisation

4. Daily baths, Perineal and rectal hygiene 
5. Oral care after meals.

The flow chart of management of Neutropenia is depicted in figure 1 .

Suggested guidelines for the hospitalised neutropenic patients include

- Wash hands frequently and thoroughly
- Place the patient in a private room

- Screen visitors for contagious diseases.

- Clean and disinfect equipments before patient contact

- Use a separate stethoscope for the patient and disinfect after each use.

Figure 1: Management of neutropenia.

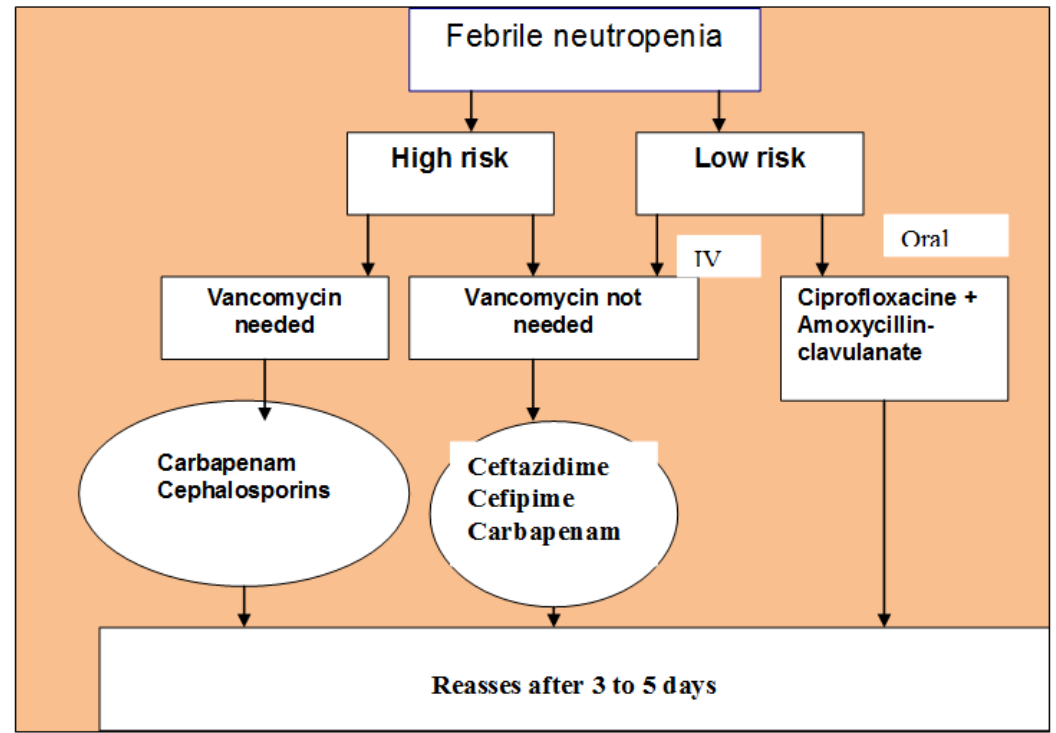

Table 4: Emetic potential of single chemotherapeutic agents.

\begin{tabular}{|c|c|c|c|c|}
\hline Level 1 & Level 2 & Level 3 & Level 4 & Level 5 \\
\hline $\begin{array}{l}\text { Frequency of } \\
\text { emesis }<10 \%\end{array}$ & $\begin{array}{l}\text { Frequency of } \\
\text { emesis } \\
10-30 \%\end{array}$ & $\begin{array}{l}\text { Frequency of emesis } \\
30-60 \%\end{array}$ & $\begin{array}{l}\text { Frequency of emesis } \\
60-90 \%\end{array}$ & $\begin{array}{l}\text { Frequency of emesis } \\
>90 \%\end{array}$ \\
\hline Bleomycin & Docetaxel & $\begin{array}{l}\text { Cyclophosphamide } \\
\leq 750 \mathrm{mg} / \mathrm{m}^{2}\end{array}$ & Carboplatin & Carmustine $>250 \mathrm{mg} / \mathrm{m}^{2}$ \\
\hline Busulfan & Etoposide & $\begin{array}{l}\text { Doxorubicin } \\
20-60 \mathrm{mg} / \mathrm{m}^{2}\end{array}$ & $\begin{array}{l}\text { Carmustine } \\
\leq 250 \mathrm{mg} / \mathrm{m}^{2}\end{array}$ & Cisplatine $\geq 59 \mathrm{mg} / \mathrm{m}^{2}$ \\
\hline Hydroxyurea & Gemcitabine & $\begin{array}{l}\text { Epirubicin } \\
\leq 90 \mathrm{mg} / \mathrm{m}^{2}\end{array}$ & $\begin{array}{l}\text { Cisplatine } \\
<50 \mathrm{mg} / \mathrm{m}^{2}\end{array}$ & $\begin{array}{l}\text { Cyclophosphamide } \\
>1500 \mathrm{mg} / \mathrm{m}^{2}\end{array}$ \\
\hline $\begin{array}{l}\text { Vinblastine } \\
\text { Vincristine }\end{array}$ & $\begin{array}{l}\text { Methotrexate } \\
>50 \mathrm{mg} / \mathrm{m}^{2} \\
<250 \mathrm{mg} / \mathrm{m}^{2}\end{array}$ & Idarubicin & $\begin{array}{l}\text { Cyclophosphamide } \\
>750 \mathrm{mg} / \mathrm{m}^{2} \\
\leq 1500 \mathrm{mg} / \mathrm{m}^{2}\end{array}$ & Dacarbazine \\
\hline
\end{tabular}

\section{Thrombocytopenia}

A moderate risk of bleeding exists when the platelet count falls to less than 50,000 cells $/ \mathrm{mm}^{3}$ and major risk is associated with the platelet count falls to less than 10,000cells $/ \mathrm{mm}^{3}$. Clinical manifestations include increased bruising, purpura, petechiae, oozing from mucosal surfaces. Drugs causing Thrombocytopenia are given in Table 3.5

\section{Management}

Mild moderate thrombocytopenia is managed with platelet transfusion. ${ }^{12}$ The usual dose of platelets is 4 to 6 units of random donor platelets and one unit of single 
donor aphaeresis platelets. In an attempt to reduce platelet transfusion Recombinant human interleukin11 (Oprelvekin) was approved by the FDA and reduced the need for platelet transfusion but was associated with a wide range of cardio pulmonary side effects.

Figure 2: Mechanism of vomiting.

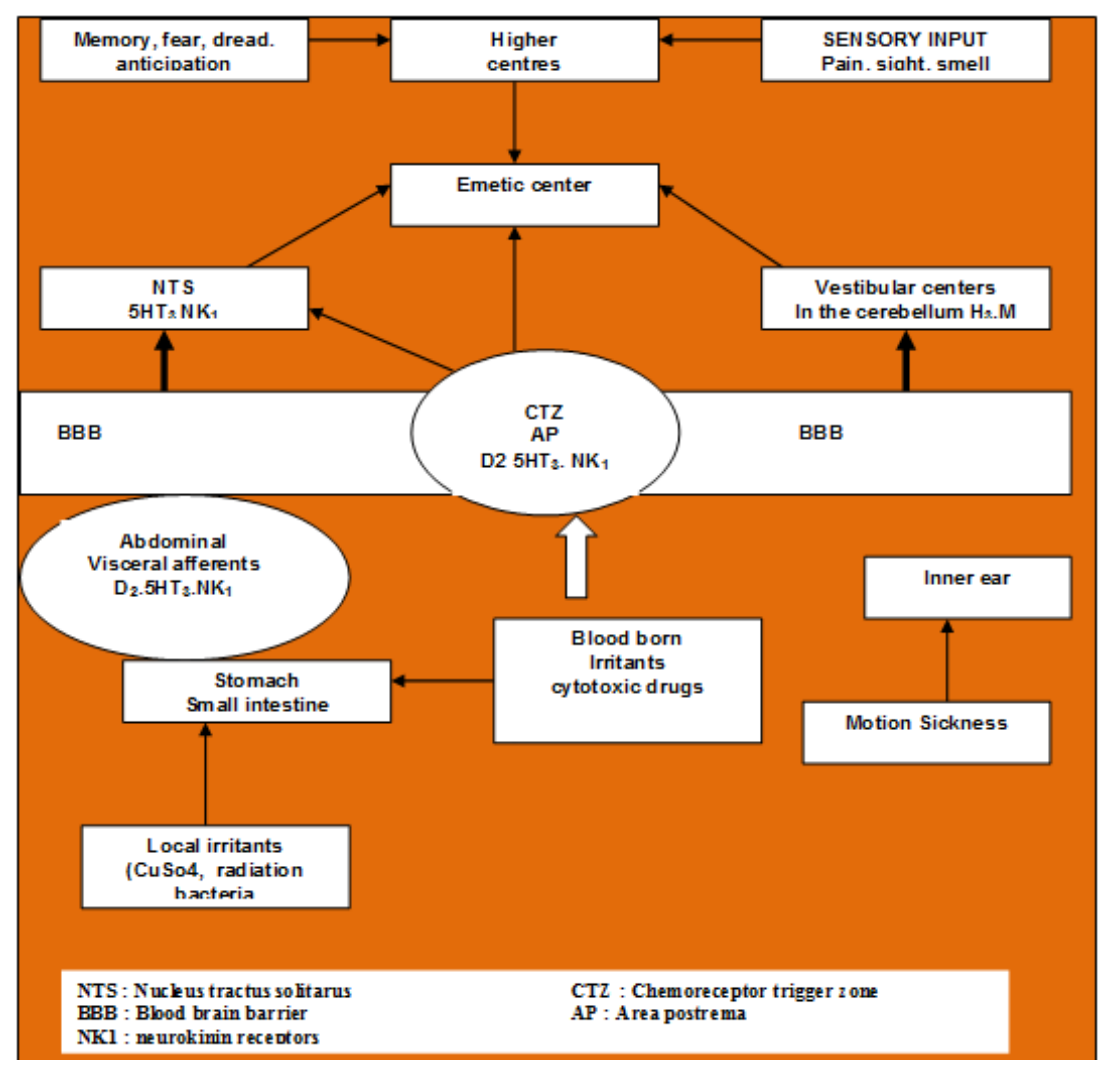

\section{GASTROINTESTINAL TOXICITY}

Anorexia, nausea and vomiting are frequently observed after chemotherapy. It is not a pathological process but rather a physiological process in which the body attempts to rid itself of toxic substances. This reaction is controlled by a reflex are with multiple afferent limbs, a coordinating area (vomiting centre) and multiple efferent pathways that activate and coordinate the muscle group necessary for a successful emetic response (figure 2). The afferent limb includes 1. CTZ pathway in which substances released into the CSF, activate the trigger zone, 2. The peripheral pathway initiated by relevant neurotransmitter receptors via, vagus nerve, 3. Cortico spinal pathway activated by learned association, 4. Vestibular pathway. Patients who are about to begin chemotherapy are apprehensive about nausea and vomiting. Nausea and vomiting can be distressing enough to the patient to cause extreme physiologic and psychological discomfort culminating in withdrawal from therapy. Commonly nausea begins 4 to $6 \mathrm{hrs}$ after treatment and lasts for 1 to 2 days. Chemotherapeutic agents are classified into highly emetic, moderately emetic, mild emetic according to their emetic potential. ${ }^{13}$ This is shown in Table 4.

\section{Management}

The goal of therapy is to prevent the three phases of nausea and vomiting. Anticipatory vomiting occurs before the treatment is administered, acute vomiting follows within the first 24 hours after the treatment and that which occurs more than 24 hours after the treatment is delayed vomiting. Combination of 5- $\mathrm{HT}_{3}$ antagonist and corticosteroids is the gold standard for acute antiemetic protection. Prevention of acute nausea and vomiting is by serotonin (5HT3 antagonists) like Ondansetron, Granisetron, \& Corticosteroids for high to moderate to emetic potential drugs. For low emetic potential drugs, corticosteroid and an antiemetic drug are used. High dose Metoclopramide functions both as a D2 receptor antagonist and $5-\mathrm{HT}_{3}$ receptor antagonists and has significant antiemetic action. ${ }^{14-15}$ Antiemetics used are shown in Table 5. In addition patient may benefit from the use of non-pharmacological interventions like music therapy, self-hypnosis, massage therapy etc.

\section{ORAL TOXICITY}

The normal orolabial or buccal mucosa has a turnover rate of 5 to 16 days and is at increased risk cytotoxic effects of chemotherapy. Since most patients are unaware of the toxicity, oral disease is common in subjects undergoing chemotherapy. The mucosa can be secondarily infected, if 
once ulcerated rendering a portal for systemic infection ${ }^{16}$. The normally proliferating epithelial lining is damaged and rate of renewal of mucosal lining is slowed. This results in stomatitis, dysphagia, diarrhoea, oral ulceration, oesophagitis, \& proctitis with pain and bleeding. ${ }^{15}$ The likelihood of the development of stomatitis from a drug is dependent on the agent, the dose and schedule of administration. Specific anticancer agents ${ }^{16}$ that may cause stomatitis are depicted in Table 6.

Table 5: Class of antiemetic used.

\begin{tabular}{|ll|}
\hline Class of antiemetics & Drug \\
\hline Antihistamines & Cinnarizine \\
Benzodiazepines & Lorazepeam \\
Anticholinergic drugs & Hyoscine \\
Dopamine inhibitors & Phenothiazines \\
Corticosteroids & Dexamethasone \\
5-HT3antagonists & Ondansetron \\
Prokinetic drugs & Metoclopramide \\
$\begin{array}{l}\text { NK1 receptor } \\
\text { antagonists }\end{array}$ & Substance P antagonists \\
\hline
\end{tabular}

Table 6: Drugs causing stomatitis.

\begin{tabular}{|ll|}
\hline Antimetabolites & $\begin{array}{l}\text { Methotrexate, 5-Flurouracil, } \\
\text { Cytarabine, Irinotecan }\end{array}$ \\
$\begin{array}{l}\text { Antitumor } \\
\text { antibiotics }\end{array}$ & $\begin{array}{l}\text { Doxorubicin, Dactinomycin, } \\
\text { Mitomycin, Bleomycin }\end{array}$ \\
Plant alkaloids & Vincristine, Vinblastine, Etoposide \\
Others & Alkylating agents in high doses \\
Biologic agents & Interleukins
\end{tabular}

Table 7: Agents for oral care.

Cleansing agents
Normal saline, hydrogen peroxide, sodium
bicarbonate, Chlorhexidine
Lubricating agents
Saliva substitutes, water or oil base lubricants
Analgesic agents
Healing \& coating agents
Sucralfate, Vitamine E, Antacids, Allopurinol
Topical anaesthetics
Lidocaine, Benzocaine, Diclomine hydrochloride
Systemic analgesics
NSAID, Narcotic analgesics

\section{Management}

Prevention by good nutrition, dental hygiene and early detection are mandatory. Management of oral complications are by cleansing agents, lubricating agents and analgesic agents like topical anaesthetic and systemic analgesics. ${ }^{17-18}$ Details are provided in Table 7.Secondary oral infection should be treated promptly and accurately as possible. Fungal infections may be treated with nystatin suspension, clotrimazole or oral fluconazole. Viral infections are commonly treated with oral or IV Acyclovir.

\section{CONSTIPATION}

In patients whose cancer has resulted in debility or immobility, or in those who require narcotic analgesics, constipation can be a particular problem. Many medications can cause constipation. Opioids are the primary agents. They cause inhibition of contraction of longitudinal smooth muscles and secretion of intestinal transit time. There is subsequent increased intestinal absorption of fluid and electrolytes. Constipation may also develop in patients who have received neuro toxic chemotherapeutic agents. Decreased bowel motility due to intra abdominal disease, hyper calcemia or dehydration can also contribute to constipation. ${ }^{19}$ Risk factors for constipation are mentioned in Table 8.

Table 8: Risk factors for constipation.

\begin{tabular}{|ll|}
\hline Opioids & Hypercalcemia \\
Immobility & Hypokalemia \\
Old age & Vinca alkaloids \\
Decrease oral intake & Corticosteroids \\
\hline
\end{tabular}

\section{Management}

Chronic constipation is a problem in patients with cancer that is more easily prevented than treated. Constipation can be minimised by taking a high fibre diet; rich in fresh fruits and vegetables and adequate fluids. A bowel regimen consists of initial mild stool softeners and bulk laxatives and then proceeding to stimulants or osmotic laxatives. Two of the most potent laxatives acceptable for long-term use are Lactulose \& Sorbitol. Glycerine suppositories and Bisacodyl suppositories are stool softeners.

\section{Table 9: Anticancer drugs causing diarrhoea.}

\begin{tabular}{|ll|}
\hline Methotrexate & Paclitaxel \\
Cytarabine & Irinotecan \\
Nitrosourea & Floxuridine \\
\hline
\end{tabular}

\section{DIARRHOEA}

Diarrhoea can generally be said to exist when bowl movements are excessive in both frequency and liquid content. The quantitative definition of diarrhoea is stool weight of more than $200 \mathrm{gm} /$ day. ${ }^{19}$ It has the potential to cause great morbidity. Among the many causes of diarrhoea in patients with cancer are chemotherapy, radiotherapy, cancer itself, medications, supplemental feedings, anxiety, and infection with bacteria like Clostridium difficile. Consequences of diarrhoea include dehydration, nutritional, electrolyte, albumin losses and deleterious effects on a patient's psychological immune 
and functional status. ${ }^{19}$ Table 9 shows anticancer drugs causing Diarrhoea.

\section{Management}

Identify and eliminate underlying cause. Discontinue suspected medication. Start appropriate antibiotics. Begin supportive therapy. Management of treatment related diarrhoea is symptomatic and requires little or no alteration in cancer therapy. Pharmacological management is given 12 to 24 hours later if inadequate response or immediately if grade 3 or 4 diarrhoea begin. It includes agents like kaolin, pectin, loperamide, diphenoxylate hydrochloride, Octreotide. ${ }^{20}$

\section{HAIR FOLLICLE TOXICITY}

Alopecia is the commonest cutaneous side effect directly related to cytotoxic effects of drugs on the rapidly proliferating cell population of the hair follicle. Chemotherapy induced hair loss is not necessarily a serious physiologic complication but psychologically it can be one of the most devastating side effects. It is due to toxic effect of drug on rapidly dividing hair bulb. It can cause severe emotional impacts in some patients. Alopecia induced by chemotherapeutic agents is dose dependant and is reversible on cessation of medication. Repetitive exposure to cytotoxic agents results in complete loss of hair. Other terminal hair follicles such as those of eyebrows, eyelashes, beard, auxiliary and pubic hairs are variably affected. The hair usually re grows normally after completion of therapy.The anti cancer drugs causing hair follicle toxicity is given in Table 10 .

Table 10: Drugs causing hair follicle toxicity.

\begin{tabular}{|ll|}
\hline Doxorubicine & Paclitaxel \\
Daunorubicine & Ifosamide \\
Cyclophophamaide & Etoposide \\
Vincristine & Methotrexate \\
\hline
\end{tabular}

Table 11: Neurotoxicity associated with cytotoxic drugs.

\begin{tabular}{|c|c|c|c|}
\hline \multirow{4}{*}{\multicolumn{2}{|c|}{$\begin{array}{l}\text { Acute myelopathy } \\
\text { Intrathecal cytarabine } \\
\text { Intrathecal methotrexate } \\
\text { Intrathecal thiotepa }\end{array}$}} & \multicolumn{2}{|c|}{ Cerebellar syndrome } \\
\hline & & \multicolumn{2}{|c|}{ Cytarabine } \\
\hline & & \multicolumn{2}{|l|}{ Procarbazine } \\
\hline & & \multicolumn{2}{|c|}{ 5-Flurouracil } \\
\hline \multicolumn{2}{|c|}{ Autonomic neuropathy } & \multicolumn{2}{|c|}{ Cranial nerve toxicity } \\
\hline Cisplatin & Vindesine & Vindesine & Carmustine \\
\hline Paclitaxel & Vinblastine & Vinblastine & Cisplatin \\
\hline Procarbazine & Vincristine & Vincristine & Ifosamide \\
\hline \multicolumn{2}{|c|}{ Encephalopathy } & \multicolumn{2}{|c|}{ Peripheral Neuropathy } \\
\hline Carmustine & Cytarabine & Vincristine & Carboplatin \\
\hline Procarbazine & 5-Flurouracil & Vinblastine & Procarbazine \\
\hline Cisplatin & Ifosamide & Vindesin & Paclitaxel \\
\hline
\end{tabular}

\begin{abstract}
Management
Interventions start with informing and preparing the patient for the possibility of alopecia. Because of the concern for scalp metastasis and sanctuary sites, scalp hypothermia is no longer recommended. Studies have shown that the use of Imuvert - a membrane vesicle ribosome preparation from a bacterium either partially or completely reverse the alopecia caused by the chemotherapeutic agents. $^{21-22}$
\end{abstract}

\section{NERVOUS SYSTEM TOXICITY}

The incidence of neurotoxicity associated with chemotherapy is increasing because of greater use of high dose chemotherapy and newer drugs causing neurotoxicity used in combination weakening the barrier found with the brain. ${ }^{23}$ Vincristine is the most important anti neoplastic agent that has dose limiting neurotoxicity. Paresthesia of hands and feet, loss of deep tendon reflexes and weakness occur in almost all patients. All these are reversible and are seeing mostly in older patients. Peripheral sensations and motor nerve axons are at risk for damage by those chemotherapeutic agents that disrupt microtubules. Subjects with diabetics, alcohol abuse and those with inflammation and toxic neuropathy are at risk for neurotoxicity. ANS toxicities are chronic constipation, bowel obstruction, and orthostatic hypotension. A paraneoplastic effect needs to be considered as a cause for persisting numbness and tingling occurring in peripheral neuropathy. ${ }^{24}$ Neurotoxicity associated with cytotoxic drugs is depicted in Table 11.

\section{Management}

The only effective therapy is discontinuation of the causative chemotherapeutic agent. Early detection and treatment of neurotoxicity by reduction of drug dose or discontinuation prevents permanent neurological damage. Assessment of symptoms of neurotoxicity should be documented on a routine basis. Tricyclic antidepressant, anticonvulsant, high dose vitamins are used in drug 
therapy. Management by a cytoprotectant like Amifostine is promising. ${ }^{25-26}$

\section{LOCAL TOXICITY}

Accidental extravasations have been reported in 0.1 to $0.6 \%$ of patients. Extravasation is an acute reaction due to leakage or infiltration of drug into the subcutaneous tissues. Cancer patients are more prone to drug extravasations because of multiple over puncture, Phlebitis, lymphodema due to prior surgery and generalised debilitation. Agents that extravasate capable of causing tissue necrosis or sloughing are vesicant drugs and that cause inflammation or pain at the site of extravasations are irritant drugs. ${ }^{27-28}$ The extravasated agents lead to the release of free radicals that are toxic to the tissues. The ability of the agent to bind to DNA further impedes the ability of the damage tissue to heal. Drugs which are vesicants and irritants are mentioned in Table 12

Table 12: Anticancer drugs causing extravasations.

\begin{tabular}{|ll|}
\hline Vesicants: & Irritants: \\
Doxorubicin, & Etoposide, Carmustine, \\
Daunorubicin, & Darcarbazine, Paclitaxel, \\
Mechlorethamine, & Teniposide \\
Mitomycin, Vinblastine, & \\
Vincristine, Iodorubicin & \\
\end{tabular}

\section{Management}

Management of drug extravasations is controversial. ${ }^{28}$ It includes general care and use of specific antidotes like sodium thiosulphate and hyaluronidase. ${ }^{28}$ General procedures are

1. Stop administration of chemotherapeutic agents

2. Leave the needle in place and immobilise the extremity.

3. Aspirate any residual drug in the tubing, the needle or the suspected extravasation site.

4. Remove the needle

5. Avoid applying pressure to the extravasations' site.

6. Inject appropriate antidote drug.

7. Apply warm or cold compresses.

8. Elevate the arm.

Antidotes for vesicants and irritants are Sodium Thosulfate for Mechlorethamine and Hyaluronidase for Vincristine, Vinblastine, Vindesin, Etoposide. Non pharmacological antidotes like topical cooling are used for Doxorubicin and Daunorubicin.

\section{HYPER SENSITIVITY \& ANAPHYLAXIS}

All chemotherapeutic agents can cause anaphylaxis. The drug most commonly associated with anaphylaxis is Lasparginase. Factors that increase the incidence and degree of hypersensitivity include the route of entry, amount of antigen introduced, rate of antigen absorption, specific chemotherapeutic agent, and prior exposure to the drug and the hypersensitivity of the individual to the drug. ${ }^{29}$ Chemotherapeutic drugs have been associated with all four types of hypersensitivity reactions but Type 1 reactions are observed most frequently in clinical practise. It is an allergic reaction that is $\mathrm{IgE}$ mediated. The rapid release of various mediators like histamine, prostaglandins are responsible for the symptoms produced primarily affecting the cvs, git, cutaneous \& respiratory system. Anticancer drugs causing hypersensitivity are shown in Table 13.

Table 13: Drugs causing hypersensitivity.

\begin{tabular}{|ll|}
\hline Carboplatin & Doxorubicin \\
Cisplatin & Daunorubicin \\
Cyclophospamide & Ifosamide \\
Cytarabin & L-asparginase \\
Paclitaxel & Docetaxel \\
& \\
\hline
\end{tabular}

\section{Management}

Prophylactic premedication with corticosteroids, histamine antagonists or both prevent possible reactions. Graded scaling for anaphylactic symptoms must be done. Drugs, which cause these reactions, should be administered under supervision. Carefully assess patients for clinical signs and symptoms. Have emergency drugs available and accessible. Once a reaction occurs immediately stops the infusion. Assess airway, breathing and circulation. Closely monitor the patient's vital signs. Administer oxygen as needed and IV fluids. Document the reaction, treatment and patient response.

\section{METABOLIC ABNORMALITIES}

A rapid destruction of tumour cells by anticancer drugs results in increased metabolism of nucleic acid, released from these cells. This increases the uric acid level precipitate nephrotoxicity. Massive tumour lysis releases intracellular potassium and phosphate causing severe hyperkalemia and hyperphosphatemia leading to hypocalcaemia and is called tumour lysis syndrome. ${ }^{30}$ Hyponatremia due to inappropriate secretion of antidiuretic hormone is seen with cyclophosphamide and vincristine.

\section{Management}

Patient who have tumour lysis syndrome must have adequate hydration with half normal saline solution. 
Hyperkalemia, hyperphosphatemia and hypocalcaemia should be treated accordingly. ${ }^{31}$

\section{HEPATIC TOXICITY}

Hepatic toxicity is a common problem in cancer chemotherapy. Virtually most subjects undergoing chemotherapy have exposure to hepatotoxins including medication and alcohol. Some may have coexisting liver disease. $^{31}$ Some because of immunocompromised state may be prone to infection. Hepatotoxicity reactions may occur in a varying pattern including parenchymal cell injury with necrosis, fibrosis, ductal injury with cholestasis, \& hepatic venoocclusive disease. Chemotherapeutic agents that cause hepatotoxicity produce a predictable pattern of injury where the mechanism is direct or idiosyncratic. Drugs causing hepatotoxicity are given in Table $14 . .^{32-33}$

Table 14: Drugs causing hepatotoxicity.

\begin{tabular}{|ll}
\hline Cyclophosphamide & Methotrexate \\
Streptozocin & 6-Mercaptopurine \\
5-Flurouracil & Doxorubicin \\
\hline
\end{tabular}

\section{Management}

Depending on the condition of patient discontinuation of drugs, reduction in dose or intermittent therapy is done other than supportive management. Defibrotide can reverse the venoocclusive disease of liver caused by all drugs at high doses except cisplatin.

\section{RENAL TOXICITY}

Major risk factors for renal toxicity in patients with cancer include nephrotoxic chemotherapy drugs, age, nutritional status, use of nephrotoxic drugs, pre-existing renal dysfunction. ${ }^{34}$ Of these impaired renal function is the most significant risk factor. Acute renal failure and haemolytic uremic syndrome are serious and fatal complications. Drugs causing renal toxicity are depicted in Table 15 .

Table 15: Drugs causing renal toxicity.

\begin{tabular}{|ll|}
\hline Cisplatin & Plicamycin \\
Ifosamide & Streptozotocin \\
Mitomycin & \\
\hline
\end{tabular}

\section{Management}

Assess the renal function and evaluate the risk factors before initiating therapy. Plasma concentration of blood urea nitrogen and creatinine are common assessment parameters. 24 hour collection of urine for creatinine clearance is recommended to monitor patients and alter drug doses to prevent or minimize renal toxicity. ${ }^{34}$ Thiophosphate Cytoprotectants like Amifostine can counteract cisplatin induced nephrotoxicity. ${ }^{35}$

\section{URINARY TRACT TOXICITY}

It varies from renal tubular damage by Cisplatin and Methotrexate to haemorrhagic cystitis (10\%) by cyclophosphamide. ${ }^{36}$ An increased incidence of bladder carcinoma has been associated with prolonged use of these drugs. Contact of bladder wall with toxic metabolites of cyclophosphamide like acrolein produces mucosal erythema, inflammation, ulceration, necrosis and a reduced bladder capacity. ${ }^{37}$ The symptoms include hematuria and dysuria.

\section{Management}

The Acrolein conjugator, MESNA mercaptoethanesulphonatesodium) acts by binding to acrolein and result in a non toxic Thioether. The use of MESNA and hydration significantly reduce the incidence of bladder toxicity with Ifosamide or high dose Cyclophosphamide. Acetylcysteine is a sulfhydryl compound used for the same purpose. Depending on the degree of toxicity, bladder irrigation, and fulguration and in rare instances cystectomy may be warranted.

\section{PULMONARY TOXICITY}

Chemotherapeutic drugs can damage directly or indirectly, lung tissue both of endothelial and epithelial cells. ${ }^{38}$ Clinical presentations of pulmonary toxicity are acute pneumonitis, pulmonary fibrosis, hypersensitivity pneumonitis, non cardiogenic pulmonary edema. Many patients will exhibit symptoms and histological findings of more than one type of toxicity. Drugs causing pulmonary toxicity are mentioned in Table 16.

Table 16: Drugs causing pulmonary toxicity.

\begin{tabular}{|ll|}
\hline Acute pneumonitis & Pulmonary fibrosis \\
Bleomycin & Bleomycin \\
Vinca alkaloids & \\
Methotrexate & \\
Procarbazine & \\
Carmustine & \\
Mitomycin & \\
Hypersensitivity & Non cardiogenic \\
pneumonitis & pulmonary edema \\
Procarbazine & Cyclophosphamide \\
Azathioprine & Methotrexate \\
Bleomycin & Cytarabin \\
Methotrexate & Mitomycin \\
& \\
\hline
\end{tabular}

\section{Management}

It includes discontinuation of the drug and administration of corticosteroids and supportive care.

\section{CARDIAC TOXICITY}

Cardiomyopathy is the most common chemotherapy associated cardiac toxicity and is thought to be due to free radical mediated injury. ${ }^{39}$ Myocardial ischemia, 
pericarditis, arrhythmia, ECG changes and angina occur much less frequently. ${ }^{40-41}$ The anthracyclines have the highest risk for cardiomyopathy which is cumulative dose response related. Acute effects occur within hours of bolus administrations include arrhythmia, sinus tachycardia, ECG changes are transient and no dose related. Sub acute cardiomyopathy may present during or weeks to months after therapy or within one year of treatment. Later onset cardiac toxicity occurs one to five years after treatment. ${ }^{42}$

\section{Management}

The primary management strategy of Anthracycline cardiac toxicity is prevention and early detection. Use of cardioprotectant iron chelator, Dexrazoxane represents the primary prevention approach. ${ }^{43}$

Table 17: Difference between secondary neoplasms.

\begin{tabular}{|c|c|c|}
\hline & $\begin{array}{l}\text { Alkylating } \\
\text { agent induced }\end{array}$ & $\begin{array}{l}\text { Topoisomerase II } \\
\text { induced }\end{array}$ \\
\hline $\begin{array}{l}\text { Preceding } \\
\text { phase of MDS }\end{array}$ & Yes & No \\
\hline Type of AML & M1,M2 & M4,M5 \\
\hline $\begin{array}{l}\text { Induction } \\
\text { phase }\end{array}$ & Long & Short \\
\hline Cytogenetics & $\begin{array}{l}\text { Loss of whole } \\
\text { chromosome } 5,7 \\
\& \text { both }\end{array}$ & $11 q 23,21 q 22,3 q 23$ \\
\hline
\end{tabular}

\section{MISCELLANEOUS}

\section{Secondary cancer}

In spite of the improvement in survival of patient with cancer second cancer is emerging as a problem since they can cause substantial mortality and morbidity. Chemotherapy is far more potent in inducing secondary leukaemia. ${ }^{44}$ The two major syndromes of toxicity are classical alkylating agent related and topoisomerase II related. ${ }^{45}$ Difference between secondary neoplasms is depicted in Table 17.

\section{Hyper pigmentation}

These are primary toxic skin reactions induced by cytotoxic agents. ${ }^{46}$ Hyper pigmentation can be on skin, mucous membrane, nails, hair and teeth. Drugs causing nail changes \& Pigmentation are shown in Table 18.

Table 18: Drugs causing nail changes \& pigmentation.

\begin{tabular}{|c|c|}
\hline $\begin{array}{l}\text { Drug causing nail } \\
\text { changes }\end{array}$ & $\begin{array}{l}\text { Drug causing } \\
\text { hyperpigmentation }\end{array}$ \\
\hline Bleomycin & Bleomycin \\
\hline Cyclophosphamide & Cyclophosphamide \\
\hline Doxorubicin & Busulfan \\
\hline 5-Flurouracil & Carmustine \\
\hline Hydroxyurea & Dactinomycin \\
\hline Paclitaxel & Methotrexate \\
\hline
\end{tabular}

\section{Radiation recall reactions}

Radiation is known to produce long standing arterial endothelial injury which may be exacerbated by anticancer drugs especially doxorubicin, dactinomycin. ${ }^{46}$

\section{Gonadal toxicity}

Many chemotherapeutic agents can cause gonadal dysfunctions in both sexes and in all age groups. It can cause menstrual irregularities and premature menopause in women, oligospermia and infertility in men. ${ }^{47}$ The side effects are related to agents used total dosage and duration of administration, age and sex. Some have teratogenic potential. Gonadal dysfunction as a consequence of treatment with alkylating agents was reported and these drugs remain the most significant gonadal toxins. ${ }^{48}$ Effects of chemotherapy on the reproductive system are: Germ cell depletion, loss of gonadal function, mutagenic changes of germinal cell, teratogenic effects in foetus, seminiferous tubules dysfunction.

\section{Occular toxicity}

Occular toxicity caused by chemotherapeutic agents manifested as cataract, papillary, oedema, bilateral optic nerve swelling, and conjunctivitis. ${ }^{49}$

\section{Ototoxicity}

Ototoxicity can be cochlear and vestibular. Rapid drug delivery, concurrent administration of amino glycoside, antibiotics and cranial irradiation potentiate ototoxicity. ${ }^{50}$

All these toxicities can be managed by prevention and early detection.

\section{CONCLUSION}

Advances in chemotherapy have provided important proof of the principle that anti cancer drugs can cure cancer, and subsequently have been integrated into treatment programmes with surgery and radiation therapy. The primary obstacles to the clinical efficacy of chemotherapy have been the toxicity to the normal tissues of the body. Rapidly proliferating tissues such as bone marrow, gastrointestinal tract, hair follicle etc are the major sites of acute toxicities. In addition chronic and cumulative toxicities may also occur. It includes hazards during handling of cytotoxic drugs and its interaction with other drugs. There are measures and agents which can ameliorate the toxicities of anticancer drugs. This paper summarises the systemic toxicities of anticancer drugs, common antineoplastic agents causing these toxicities and measures adopted for its management. Proper management of toxicities are utmost importance because it affects the course of treatment and outcome of the patient in his physical, mental and social wellbeing.

\section{ACKNOWLEDGEMENTS}

The author thanks Dr. Sreejith Nair, Professor of Medical Oncology, Regional Cancer Centre, Trivandrum for his valuable guidance. 


\section{REFERENCES}

1. Devita VT, Hellman S and Rosenberg SA, Principles and Practise of Oncology, $6^{\text {th }}$ edition, Lippincott Williams and Wilkins 2256-315.

2. H. P. Rang, M. M. Dale \& J. M. Ritter, Anticancer drugs, Text book of Pharmacology, Elsevier; 2012; $7^{\text {th }}$ edition: $673-87$.

3. George M. Brenner, Craig W. Stevens, Antineoplastic drugs, Text book of Pharmacology, Saunders Elsevier, 2010 ; $3^{\text {rd }}$ edition: 493-511.

4. Gupta S, Tannous R and Friedman M. Incidence of anaemia in CHOP-treated intermediate- grade nonHodgkin's lymphoma (IGNHL). Euro J Cancer. 2001; S94:339.

5. H. Clark Hoagland, Dennis A Gastineau, Haematological complications of cancer chemotherapy, The chemotherapy source book, Michael C Perry, $1992 ; 2^{\text {nd }}$ edition: 559.

6. American Society of clinical Oncology recommendations for the use of Hematopoietic CSF, Evidence based clinical practise guidelines. J Clin Oncol 1994; 12: 2471-508.

7. Stacey L Berg, Frank M Balis, and David G Pop lack: Cancer Chemotherapy: Haematology of infancy and childhood, Nathan and Oski's, 1998; $5^{\text {th }}$ edition: 1218 .

8. Furie B, Cassileth PA, Atkins MB and Mayer RJ. Clinical haematology and oncology: presentation, diagnosis, and treatment: Chapter 66, (First Edition) Churchill Livingstone, Philadelphia, 2003; 636-47.

9. Doordujin JK, van der Holt B, van Imhoff GW, van der Hem KG, Kramer MH, van oers MH etal. CHOP compared with $\mathrm{CHOP}$ plus granulocyte stimulating factor in elderly patients with aggressive non Hodgkin's Lymphoma. J Clin Oncol 2003; 21:304150.

10. Pizzo PA, Schimpff. Strategies for the prevention of infection in myleosuppressed cancer patients. Cancer Treat Rev 1983; 67:223-34.

11. Hughes WT. 2002 guidelines for the use of antimicrobial agents in neutropenic patients with cancer. Clin Infect Dis 2002; 34:730-751.

12. Schiffer CA, Anderson KC, Benet. Platelet transfusion for patients with cancer; Clinical practise guidelines of the American Society, Clinical oncology. J Clin Oncol 2001; 19:1519-38.

13. Rittenberg CN. New class of antiemetic agents on horizon. Clin J Oncol Nurs 2002; 6:103-4.

14. Douglas Peterson, NC Shubert. Cancer chemotherapy source book, Michel C Perrie; 2001; 3:406-24.

15. Sharma R., Tobin P and Clarke SJ. Management of chemotherapy-induced nausea, vomiting, oral mucositis, and diarrhoea. Lancet Oncol 2005; 6: 93102.

16. Main BE, Calman KC, Ferguson MM, Kaye SB, Mac Far lane TW, Mairs RJ et al. The effect of cytotoxic therapy on saliva and oral flora. Oral Surg Oral Med Oral Pathol 1984; 58:545-8.
17. Sonis S, and Clark J. Prevention and management of oral mucositis induced by antineoplastic therapy, Oncology (Williston Park) 1991; 5:11-8.

18. Peterson DE. Research advances in oral mucositis. Curr Opin Oncol 1999; 11: 261-66.

19. Diana S Early. Gastrointestinal complication of chemotherapy, Cancer chemotherapy source book, Michel C Perrie 2001; 3:427-31.

20. Gibson RJ and Stringer AM. Chemotherapy-induced diarrhoea, Current Opinion Support Palliative Care 2009; 3:31-5.

21. Joaquin J Jimenez, Hui-Sheng Huang and Adel A Yunis. Treatment with ImuVert/JV-Acetyl cysteine Protects Rats from Cyclophosphamide / CytarabineInduced Alopecia. Cancer Invest 1992; 10:271-6.

22. Jimenez JJ, Sawaya ME, and Yunis AA. Interleukin 1 protects hair follicles from cytarabine (ARA-C)induced toxicity in vivo and in vitro. FASEB J 1992; 6:911-3.

23. David R. Macdonald; Neurotoxicity of chemotherapeutic agents, The Chemotherapy source book, Michael C Perry. ${ }^{2 \text { nd }}$ edition 1996:752-54.

24. Klaas Hoekman, Wim J F, van der vijgh and Jan B Vermorkan: Clinical and Preclinical Modulation of Chemotherapy induced toxicity in patients with Cancer. Drugs 1999; 57:133-5.

25. Asna N, Lewy H, Ashkenazi IE et al. Time dependent protection of amifostine from renal and hematopoietic cisplatin induced toxicity. Life Sci 2005; 76:1825-34.

26. Bukowski RM. The need for cytoprotection. Eur J Cancer 1996; 32A Suppl 4:S2-4.

27. Janet M Tepton, Rolland T Steel. Acute reaction and short-term side effects of cancer chemotherapy, Handbook of cancer chemotherapy; 5th edition: 5557.

28. Reilly JJ, Neifield JP, Rosenberg SA. Clinical course and management of accidental Adriaycin extravasations. Cancer 1977; 40:2053-6.

29. Harwitz.N. Predisposing factors in adverse reactions to drugs. Br Med J 1969; 1:536-9.

30. Rolland T Skeel. Handbook of Cancer Therapy, Lippincott Williams and Wilkins $5^{\text {th }}$ edition: 630-2.

31. Shibata H. Treatment for the electrolytic disorders in cancer patients. Gan to Kagaku Ryoho 2008; 35:2330-3.

32. Bohannon Costa. Hepatotoxicity following VCR therapy. Cancer 1984; 54:2006-8.

33. Paul D King and Michael C Perry. Hepatotoxicity of chemotherapeutic agents, The Chemotherapy source book, Michael C Perry, 1996; $2^{\text {nd }}$ Edition:710.

34. Paterson WB, Reams GP. Renal toxicities of Chemotherapy, Semin Oncol 1992; 19:521-8.

35. Santini V. Amifostine: chemotherapeutic and radiotherapeutic protective effects. Expert Opin Pharmacother 2001; 2: 479-89.

36. Stillwell TJ, Benson RC. Cyclophosphamide induced haemorrhagic cystitis. Cancer 1988; 61:4517. 
37. Weiss R B. Nephrotoxicity, Principles and Practise of Oncology, Lippincott Williams and Wilkins; $6^{\text {th }}$ edition : 2968-70.

38. Kreisman H, Wolkove N. Pulmonary toxicity of antineoplastic therapy. Semin Oncol 1992; 19:50820.

39. Keizer HG, Pinedo HM, Schuurhuis GJ and Joenje H. Doxorubicin (adriamycin): a critical review of free radical-dependent mechanisms of cytotoxicity. Pharmacol Ther 1990; 47:219-31.

40. Michael C S Ewer and Robert S Benjamin. Cardio toxicity of chemotherapeutic drugs, The Chemotherapy source book, $2^{\text {nd }}$ edition, Michael C Perry; 1996: 651-9.

41. Donald C Boll and John. W Yarbro. Vascular toxicity, the chemotherapy source book, 2nd edition, Michael C Perry, 1996:767-75.

42. Hardy D, Liu CC, Cormier JN, Xia R, Du XL. Cardiac toxicity in association with chemotherapy and radiation therapy in a large cohort of older patients with non-small-cell lung cancer. Ann Oncol 2010; 21:1825-33.

43. Russo A, Mitchell JB. Potentiation and protection of doxorubicin cytotoxicity by cellular glutathione modulation. Cancer Treat Rep 1985; 69: 1293-6.

44. Auletta JJ, Shurin S. Improved haematopoiesis using amifostine in secondary myelodysplasia. J Paediatric Hematol Oncology 1999; 21:531-4.

45. Sessions J. Chronic Myeloid Leukaemia in 2007. Am J health Sys Pharm 2007; 64:S4-S9.

46. Coppell $\mathrm{R}$ Bohee. Cutaneous reaction to chemotherapeutic agents. American Journal of Medical Sciences 2001; 321:327-35.

47. Feldman DR, Bosl GJ, Sheinfeld J and Motzer RJ. Medical treatment of advanced testicular cancer, JAMA 2008; 299:672-84.

48. Wolf JK, Dwayne JA. Gene therapy for ovarian cancer. Int J Oncol 2002; 21:461-8.

49. Linda J Burns. Ocular side effects of chemotherapy, The Chemotherapy source book, $2^{\text {nd }}$ edition, Michael C Perry; 1996:638.

50. M N G Dukes. Meylers side effects of drugs, An Encyclopaedia of Adverse reactions and Interactions, 11th Edition; 1988: 952. 